Original Article (short paper)

\title{
The effect of different physical therapy procedures in ultramarathons
}

\author{
Priscila dos Santos Bunn ${ }^{1,2,3}$ (D), Bruno de Souza Terra ${ }^{1}$ (D), Márcio Puglia Souza ${ }^{1}$ (D), \\ Viviane Pereira de Souza Amaral ${ }^{1}$ (D), Allan Inoue Rodrigues ${ }^{1,2}$ (D), \\ Kevin Alexander Barreto Magno ${ }^{1}$ (D), Daniel de Souza Alves ${ }^{1,3}$ (D), Elirez Bezerra da Silva ${ }^{2}$ \\ ${ }^{\prime}$ Marinha do Brasil, Centro de Educação Física Almirante Adalberto Nunes, Laboratório de \\ Pesquisa em Ciências do Exercício, Rio de Janeiro, RJ, Brasil. \\ ${ }^{2}$ Universidade do Estado do Rio de Janeiro, Instituto de Educação Física e Esportes, Programa \\ de Pós-Graduação em Ciências do Exercício e do Esporte, Rio de Janeiro, RJ, Brasil. \\ ${ }^{3}$ Programa de Pós-Graduação em Desempenho Humano Operacional, Rio de Janeiro, RJ, Brasil.
}

\begin{abstract}
Aims: To analyze the effects of physical therapy procedures in reducing acute pain in runners. A second aim was to investigate the impact of weather conditions on the number of physical therapy visits during the Ultramarathon Rio24 h. Methods: This retrospective study was performed at the Physical Education Center Admiral Adalberto Nunes (CEFAN). Medical records were analyzed. The participants were athletes that were attended by the Physical therapy team during three editions of the Ultramarathon Rio2 $4 \mathrm{~h}$. The variation in the Visual Analog Scale score (VAS) before and after each treatment were analyzed. After the evaluation procedure, another professional had decided the best procedure for the assessed athlete: massotherapy, cryotherapy by immersion, or stretching. An ANOVA was performed to assess which procedures produce pain reduction immediately after the procedure. Results: A total of 1,995 care services (228 in women) were performed in 602 athletes ( 84 women). Analyzing the treatments that used only one modality ( $\mathrm{n}=512$ visits), the final pain decreased significantly over the initial pain for the three treatments. It was verified that massotherapy, cryotherapy, and stretching promote significant intragroup differences, with no intergroup differences. The environmental conditions were not associated with the number of visits. Conclusion: Massotherapy, cryotherapy, and stretching are effective treatments for acute pain reduction during ultramarathons. The weather conditions are not associated with the number of physical therapy visits.
\end{abstract}

Keywords: running, athletic injuries, physical therapy modalities.

\section{Introduction}

Ultramarathon races are any foot race with distances longer than the traditional marathon $(42,195 \mathrm{~m})$. It can be performed with a distance or time-specific and take place on trail, track, or road ${ }^{1,2}$.

Ultramarathon athletes have a high volume of training $^{3}$. They spend $8.9 \pm 4.4 \mathrm{~h}$ of running training per week and complete $85.0 \pm 35.8 \mathrm{~km} /$ week while running at a mean speed of $10.5 \pm 1.5 \mathrm{~km} / \mathrm{h}$. In elite athletes, training has a high volume, well above the volume of $145.3 \pm 23.3$ $\mathrm{h}$ per week. Regarding speed, ultramarathoners train at $10.2 \pm 2.2 \mathrm{~km} / \mathrm{h}$, being significantly slower than marathoners, who run $11.0 \pm 1.4 \mathrm{~km} / \mathrm{h}^{4}$. A high volume of training is a strategy used by ultramarathoners to prevent musculoskeletal problems ${ }^{5}$, as over $90 \%$ of athletes report pain during ultramarathon ${ }^{6}$, a high percentage compared to other sports or running events, with a higher rate. The proportion of injured individuals requiring medical assistance during ultramarathons is $65.6 \%$ versus $0.9 \%$ in road runners ${ }^{7}$. Lower limb pain, especially the knee and ankle, is the most reported symptom, especially with those athletes with pre-existing injuries ${ }^{8-10}$.

During ultramarathon competitions, procedures such as massotherapy ${ }^{6,11}$, cryotherapy by immersion ${ }^{12}$, and stretching ${ }^{4}$ have been used to decrease the pain. The massotherapy technique has been reported to be effective in reducing pain during the competition ${ }^{6,13}$, but the studies are divergent regarding the technique used, the treated muscles and the type of activity, time of day, and room temperature ${ }^{13}$. Some evidence suggests that cryotherapy or cold-water immersion (CWI) can be useful in reducing pain $^{14}$ during or after athletic activities ${ }^{15,16}$. The effects are kept for up to five hours after the end of the immersion period in cold water $\left(10-15{ }^{\circ} \mathrm{C}\right.$ for approximately 5-7 $\min )^{16,17}$. Finally, a third type of ultramarathon technique is stretching ${ }^{18}$. These are also used during tests, and examples of applications are prevention of delayed onset muscle soreness (DOMS) ${ }^{19}$ and cases of pain related to the medial tibial stress syndrome and exercise-associated muscle cramps ${ }^{20}$. It is suggested that one of the causes of pain during the races are muscle spasms, which would 
cause reduced muscle blood flow. Stretching could restore the blood flow, disrupting the cycle of pain and spasm, and diminishing musculotendinous stiffness ${ }^{19}$.

Due to the high percentage of athletes experiencing pain during ultramarathons events ${ }^{6}$ and the existence of different treatment modalities, the knowledge of the most effective physical therapy procedure to decrease the acute pain during ultramarathons will be essential to guide physical therapist during the race. Therefore, this study aimed to investigate the short-term effects of three physical therapy procedures in reducing acute pain in runners during the Ultramarathon Rio $24 \mathrm{~h}$ : massotherapy, CWI, and stretching. A second objective was to investigate the impact of weather conditions on the number of physical therapy visits.

\section{Methods}

The Research Ethics Committee of the Hospital Naval Marcilio Dias approved this study (CAAE: 56383416.0.0000.5256).

\section{Study design}

This retrospective and pragmatic study was carried out at the Physical Education Center Admiral Adalberto Nunes (CEFAN). The data were obtained from medical records. The Physical therapy team attended the athletes during the $24 \mathrm{~h}$ of competition and up to one hour after the arrival in each edition (2013, 2014 and 2015). Those in charge of the treatment were physical therapists of the CEFAN with the aid of Physical therapy students.

\section{Participants}

The participants of this study were athletes enrolled in the three editions of Ultramarathon Rio $24 \mathrm{~h}$, men and women, civil and military personnel $(n=602)$.

\section{Ultramarathons Rio $24 \mathrm{~h}$}

The Ultramarathons Rio $24 \mathrm{~h}$ took place at the CEFAN, in the years of 2013, 2014, and 2015 (VI, VII, and VIII Ultramarathon Editions, respectively). The meteorological characteristics throughout the $24 \mathrm{~h}$ of competition in each edition are in Table 1 . The three Rio $24 \mathrm{~h}$ ultramarathon editions were held in the athletics track of CEFAN, which is 400 long and has a synthetic floor with eight lanes. The objective of each Ultramarathon Rio $24 \mathrm{~h}$ was to run as much as possible for $24 \mathrm{~h}$. During the three editions, athletes could rest in the lodge next to the lane, have all their daily meals, and undergo medical or physical therapy treatment.

\section{Standardization of procedures}

The team leader has conducted theoretical and practical training for those involved in the evaluation and the treatment that would be performed in the competition. The purpose was to standardize the protocol.

\section{Evaluation}

Throughout the physical therapy period, there were always four physiotherapists responsible and a variable number of physical therapy students. When an athlete sought care, an evaluation was performed by the team. The same professional was responsible for the evaluations before and after the appointments. The evaluations and interventions were performed by different professionals

Table 1 - Weather characteristics of the three editions of Ultramarathon Rio $24 \mathrm{~h}^{*}$.

\begin{tabular}{llccc}
\hline Year & Hour & Relative humidity $(\%)$ & Maximum temperature $\left({ }^{\circ} \mathbf{C}\right)$ & Minimum temperature $\left({ }^{\circ} \mathbf{C}\right)$ \\
\hline 2013 & $06: 00-12: 00 \mathrm{am}$ & 77 & 25 & 23 \\
& $12: 00-18: 00 \mathrm{pm}$ & 57 & 24 & 23 \\
$18: 00-00: 00 \mathrm{pm}$ & 64 & 23 & 21 \\
& $00: 00-06: 00 \mathrm{am}$ & 69 & 20 & 20 \\
& $06: 00-12: 00 \mathrm{am}$ & 64 & 26 & 20 \\
& $06: 00-12: 00 \mathrm{am}$ & 79 & 26 & 23 \\
& $12: 00-18: 00 \mathrm{pm}$ & 76 & 26 & 23 \\
& $18: 88-00: 00 \mathrm{pm}$ & 79 & 24 & 20 \\
& $00: 00-06: 00 \mathrm{am}$ & 94 & 20 & 20 \\
& $06: 00-12: 00 \mathrm{am}$ & 73 & 28 & 18 \\
& $06: 00-12: 00 \mathrm{am}$ & 83 & 25 & 21 \\
& $12: 00-18: 00 \mathrm{pm}$ & 72 & 26 & 20 \\
& $18: 88-00: 00 \mathrm{pm}$ & 86 & 21 & 19 \\
& $00: 00-06: 00 \mathrm{am}$ & 95 & 20 & 19 \\
& $06: 00-12: 00 \mathrm{am}$ & 79 & 27 & \\
\hline
\end{tabular}

*Data obtained from the electronic address https://www.timeanddate.com. 
independently. The evaluator recorded age, the gender of the athlete, the duration of the care, the localization of the pain, type of physical therapy procedure performed, and the perception of pain before and after each care, evaluated by the Visual Analog Scale (VAS).

\section{Therapeutic procedures}

After the evaluation procedure, another professional had decided the best procedure for the assessed athlete: massotherapy, CWI, or stretching. In general, massotherapy was indicated for athletes who intended to return to the race immediately. If the athlete decided to pause the competition temporarily, he would perform stretching (in case of muscle cramps or medial tibial stress syndrome) or CWI.

\section{Massotherapy}

Massotherapy procedures were standardized regarding the type and sequence of maneuvers, time of application, intensity, and frequency. Superficial slippage was performed for initial skin contact and sliding product distribution (neutral liquid soap diluted in water) over the treated area. Then, the deep sliding was performed to direct blood and lymphatic flow, muscle relaxation, and reduction of pain. The maneuvers of kneading (Petrissage) by compression, wringing (lateral displacement stimulation and perpendicular muscle fibers), and skin rolling were intended to maximize these effects. Finally, the deep slip was repeated. The time of care was standardized in 10 min per body segment ${ }^{21}$.

Cryotherapy by immersion

The CWI procedure was performed in a 2,000-liter pool. The water temperature was checked every $30 \mathrm{~min}$ and kept between 10 and $15{ }^{\circ} \mathrm{C}$ by the placement of blocks of ice ${ }^{22}$. After body hygiene, the athlete was instructed to keep his/her body submerged up to the height of the xiphoid process for five to seven minutes to achieve a strongest analgesic effect ${ }^{23}$. Therefore, in general, CWI performed those athletes who had no interest in immediate return to the race.

Stretching

Passive stretching, done by the physiotherapist, was performed on lower limbs. The choice of the muscular group to be stretched depending on the physical therapy assessment: quadriceps, tensor fasciae latae, hamstrings, iliopsoas, or gastrocnemius. Stretching is useful in cases of muscle cramps or with medial tibial stress syndrome ${ }^{20}$. In this case, the stretching was performed at moments of the test intervals. In order to facilitate connective tissue plastic elongation ${ }^{24,25}$ without loss in the force production upon returning to the test ${ }^{26}$, one to three repetitions from 30 seconds was standardized in order to keep the stretching position at maximum painless amplitude.

\section{Data analysis}

Initially, it was calculated the relationship between the number of participants and the number of physical therapy attendances. Subsequently, a Proportion Comparison Test was used to compare the values of the three years and to verify if the environmental conduction influenced the number of attendances. Besides, the number of physical therapy attendances was divided by race time. The intuit was to check which competition time has the greatest need for professionals. In order to evaluate the most effective procedure, the physical therapy appointments based on only one procedure were included in the study. The assumptions of normal data distribution and homogeneity of variance were verified by the KolmogorovSmirnov and Levene test, respectively. The $3 \times 2$ ANOVA, with repeated measures to assess which procedures reduced pain immediately after the physical therapy procedure for the most frequent reasons for seeking care. Tukey's post hoc for multiple comparisons was used to identify significant differences between comparison pairs. The level of significance of $\mathrm{P} \leq 0.05$ was considered. STATISTICA 7.0 StatSoft, 1984-2004 software was used for the analyses.

\section{Analysis of effect size and power}

The size of Cohen's f effect was calculated with the means and standard deviations of the stretching, massage, and cryotherapy groups following the guidelines in http:// www.gpces.com.br ${ }^{27}$. The power was calculated using GPower Software (v. 3.1), with the following entries: Cohen effect size $f=0.69$, error a equal to 0.05 , sample size equal to 512 for three groups.

\section{Results}

The participants of the three editions of Ultramarathon Rio $24 \mathrm{~h}$ consisted of 602 athletes (84 women), aged $42.3 \pm 12.7$ years. A total of 1,995 physical therapy cares was performed (228 in women), which 533, 874, and 588 occurred in 2013, 2014, and 2015, respectively (Figure 1). Of these, 512 visits consisted of performing one procedure (CWI, massotherapy, or stretching), and were included in the analysis. A total of 73 athletes did not seek assistance in the editions. The body regions with the highest incidence of pain symptoms were the lower limbs $(74.8 \%)$, followed by the upper body (3.4\%) and upper limbs $(0.8 \%)$. Massotherapy, stretching, and cryotherapy was performed 1349, 711, and 490 times during the three editions of Ultramarathon Rio $24 \mathrm{~h}$. The temperature and relative humidity of competition day 2014 were similar to the competition day 2015. However, the environmental conditions of $2013\left(57-77 \%\right.$; $\left.20-26{ }^{\circ} \mathrm{C}\right)$ was more favorable than the competition days of 2014 (73-94\%; 20-28 ${ }^{\circ} \mathrm{C}$ ) and 2015 (72-95\%; 18-27 $\left.{ }^{\circ} \mathrm{C}\right)$. The attendee/attendance ratio in 2013, 2014 and 2015 was 158/533 (0.30); 


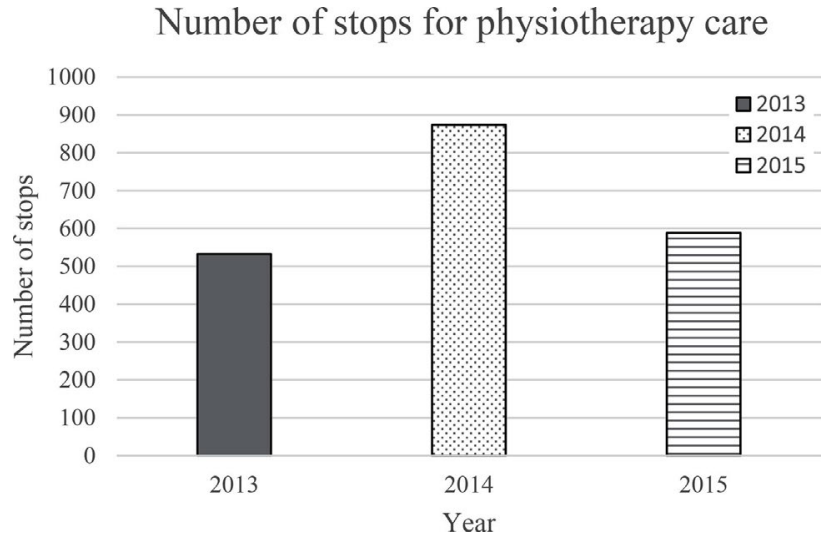

Figure 1 - Number of stops for physical therapy care in 2013, 2014 and 2015 Ultramarathon Rio 24 h editions.

232/874 (0.27); and 212/588 (0.36), respectively. The Proportion Comparison Test showed no difference between 0.30 and $0.27(\mathrm{P}=0.52)$ and between 0.30 and 0.36 $(\mathrm{P}=0.23)$; but between 0.27 and 0.36 there was difference days with similar environmental conditions $(\mathrm{P}=0.04)$.

Figure 2 lists the number of appointments divided by the 24-h competition, considering the three editions. The schedules were not registered in 34 service forms.
The results of ANOVA to evaluate the most effective treatment procedures for pain reduction are in Table 2. Treatments that used only one modality ( $\mathrm{n}=512$ visits) with massage therapy, CWI, or stretching were analyzed. Final pain decreased significantly compared to initial pain in the three treatments. In addition, the three treatment modalities promoted significant intra-group differences, with no differences between groups. Considering a Cohen $\mathrm{f}$ value of 0.69 , the present study presented a power (1error $\beta)=100 \%$.

\section{Discussion}

Massotherapy, CWI, and stretching procedures significantly reduced the acute pain during the execution of the three editions of Ultramarathon Rio $24 \mathrm{~h}$. There were 1,995 stops for physical therapy services (228 in women), which 158, 232 and 212 were assisted in 2013, 2014, and 2015 , respectively. These results differ from one previous study, which concluded that massotherapy and cryotherapy were more effective in reducing DOMS than stretching after the activity ${ }^{28,29}$.

The lower limbs were the most affected region by acute musculoskeletal symptoms at Ultramarathon Rio $24 \mathrm{~h}$. These results have already been found previously in

Table 2 - Results of ANOVA between the results of pre and post pain physical therapy procedures for the most frequent reasons for seeking care.

\begin{tabular}{lccc}
\hline Procedure & VAS pre $(\mathbf{x} \pm$ SD) & VAS post (x \pm SD) & P (intragroup) \\
\hline Stretching & $4.5 \pm 2.1$ & $1.7 \pm 2.0$ & 18 \\
Massage & $5.1 \pm 2.2$ & $1.9 \pm 2.1$ & 329 \\
Cryotherapy & $5.0 \pm 2.0$ & $2.4 \pm 2.3$ & 16.00002 \\
Total & - & - & $\mathrm{P}=0.00002$ \\
\hline
\end{tabular}

VAS $=$ Visual Analog Scale; $\mathrm{x} \pm \mathrm{SD}=$ mean \pm standard deviation

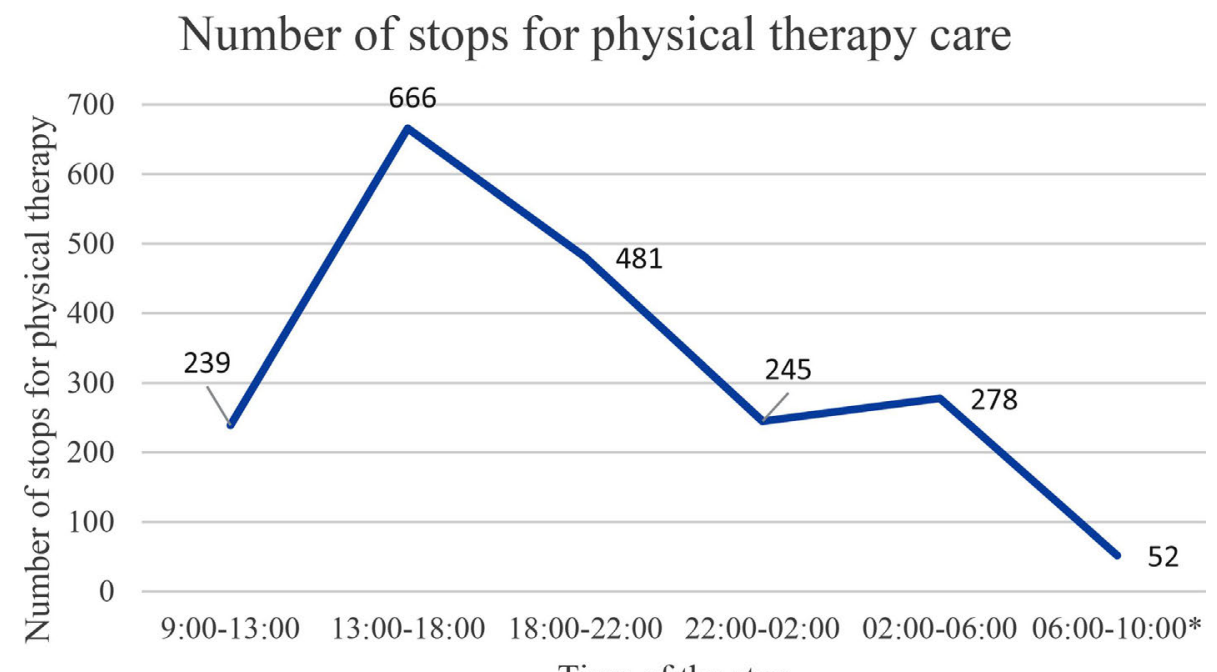

Time of the stop

Figure 2 - Number distribution of physical therapy care service for $24 \mathrm{~h} .{ }^{*}$ The tests ended at 9:00, but the physical therapy assistance went on until 10:00. 
another study conducted in other long-distance running races $^{3}$. Possibly, the repetitive landing movement and racing propulsion, in which contraction of the posterior tibial, soleus and flexor muscles of the toes occurs, can promote stress in the tibia, with consequent inflammation at the insertion of the periosteum, in addition to tendon degeneration and the plantar fasciistis ${ }^{30}$. At the same time, the high volume of exercises makes the vertical reaction force of the ground more intense in the landing phase of the race, which may exacerbate the painful symptoms ${ }^{3}$. The short-term pain-reducing effects, such as the results of the present study, may increase the permanence of the athletes and their comfort in the ultramarathon race. Probably, the temporary relief of symptoms may contribute to the maintenance of the athlete in the race ${ }^{21}$.

Massotherapy has promoted effective reductions in pain when performed for $10 \mathrm{~min}$ per segment, reinforcing results from other authors previously obtained ${ }^{31}$. These symptoms are followed by reductions in heart and respiratory rate, suggesting an effect on the sympathetic nervous system $^{32}$. Meanwhile, mechanical pressure on muscle is one of the factors suggested as inhibitors of neural excitability $^{33}$. At the same time, massotherapy seems to promote the reduction of cytokine levels, with an increase in local circulation.

With a different physiological mechanism, CWI at a temperature below $15^{\circ} \mathrm{C}$ has been used to prevent DOMS. Such reduction in pain surpasses resting alone ${ }^{34}$, resulting from the reduction of the inflammatory process and reduction in circulating creatine kinase. However, better effects are observed after $24 \mathrm{~h}$ of cryoimersion. The properties of hydrostatic pressure, vasoconstriction, and direct analgesic effect are causal factors. In athletes with DOMS, some authors have reported worsening of symptoms after $\mathrm{CWI}^{35}$. Others, who evaluated the application of CWI in competitive situations, similar to the present study, found worsening athletic performance after an immediate return to the test $\mathrm{t}^{15}$. In the present study, CWI showed significant improvement, but it was used mainly by athletes who did not intend to return immediately to the race.

In the present study, despite the small number of athletes who performed static stretching $(\mathrm{n}=18)$, shortterm pain reduction was significant. In ultramarathon events, the use of stretching has been indicated, especially in athletes with muscle cramps or with medial tibial stress syndrome. In this second case, stretching is effective when associated with $\mathrm{CWI}^{9}, 20$. On the other hand, some authors have reported increased pain after exercise in individuals who perform stretching ${ }^{28}$. This information was reinforced, years later, indicating that muscle stretching does not reduce DOMS in healthy young adults. However, if muscle pain is due to excessive prolongation of some sarcomeres in muscle fibers (such as my ultramarathon races), associated with eccentric muscle contractions, interventions that increase the number of serial sarcomeres in muscle fibers, tendon length, or adhesion may reduce muscle damage ${ }^{36}$.

Adverse environmental conditions (relative humidity and air temperature) can cause harm to the health of physical activity practitioners ${ }^{37}$. In the present study, the Proportion Comparison Test showed no difference in the proportion of participants/attendances between the day with more favorable environmental conditions (2013) compared to the days with less favorable environmental conditions (2014 and 2015). This result is reinforced when comparing the participant/attendance ratios between the competition days of 2014 and 2015, which presented similar environmental conditions. In other words, the environmental conditions in the three days of the test are not associated with the search for physical therapy care.

Despite the absence of association with environmental conditions, the analysis of the distribution of the number of care services through the $24 \mathrm{~h}$ of the test showed a higher number of stops for assistance in the afternoon and early evening (1:00 p.m. to 10:00 p.m.). Probably, as the test continues, the distance traveled goes up, increasing the incidence of pain. This trend did not continue during the night period, probably due to the athletes' rest. Therefore, it is noticeable that more physiotherapists are needed in the afternoon.

\section{Strengths and weaknesses}

Some limitations were present in this study. Many professionals involved in care may have caused performance bias, but this was the only way to take care of many athletes at the same time. Moreover, it was also not possible to evaluate the average pain values for each athlete in every stop for medical care. Despite the possibility of a cumulative effect of treatment, it was not possible to limit the number of visits, as each athlete had a different demand. It was noticeable the large variability and the small number of athletes who performed stretching $(\mathrm{n}=$ 18). Then, there is a high probability of error type II (rejecting the null hypothesis if it is false). However, the analysis of the results of 1,995 assistances throughout three years of evidence increases the external validity (pragmatism) of our results. Another limitation was the absence of musculoskeletal injuries assessment with standard reference methods. Finally, the diagnosis of the International Classification of Diseases (ICD) was not diagnosed, and some interpretation mistakes of the results could have occurred. However, this was the first study to evaluate the acute effects of different physical therapy techniques on acute pain during a 24-h ultramarathon test. Besides, a large sample size was used $(\mathrm{n}=512)$, with Ultramarathon Rio $24 \mathrm{~h}$ being the only race with such characteristics. This large sample used generated a small probability of making a mistake when affirming that the physical therapy procedures decreased pain $(\mathrm{P} \leq 0.0002)$. 
This statement was corroborated by the power calculation of the study (almost 100\%).

\section{Conclusion}

Massotherapy, cryotherapy, and stretching, performed in isolation, have positive effects of decreasing acute musculoskeletal pain in ultramarathon runners. The weather conditions are not associated with the number of physical therapy visits during the Ultramarathon Rio $24 \mathrm{~h}$.

\section{References}

1. Van Der Wall E. Long-distance running?: running for a long life?? Neth Hear J. 2014;22:89-90.

2. Schütz UHW, Billich C, König K, Würslin C, Wiedelbach $\mathrm{H}$, Brambs H-J, et al. Characteristics, changes and influence of body composition during a $4486 ? \mathrm{~km}$ transcontinental ultramarathon: results from the TransEurope FootRace mobile whole body MRI-project. BMC Med [Internet]. 2013;11:122. Available from: http://www.pubmedcentral. nih.gov/articlerender.fcgi?artid=3668188\&tool=pmcentrez\&rendertype $=$ abstract

3. Lopes AD, Carlos L, Junior H, Yeung SS, Oliveira L, Costa P. What are the Main Running-Related Musculoskeletal Injuries?? A Systematic Review. Sport Med. 2012;42 (10):891-905.

4. Knechtle B. Ultramarathon Runners?: Nature or Nurture?? Int J Sports Physiol Perform. 2012;7:310-2.

5. Rasmussen $\mathrm{CH}$, Nielsen RO, Juul MS. ORIGINAL RESEARCH WEEKLY RUNNING VOLUME AND RISK OF RUNNING ? RELATED INJURIES AMONG MARATHON RUNNERS. 2013;8(2):111-20.

6. Visconti L, Capra G, Carta G, Forni C, Janin D. Effect of massage on DOMS in ultramarathon runners: A pilot study. J Bodyw Mov Ther [Internet]. 2015;19(3):458-63. Available from: http://linkinghub.elsevier.com/retrieve/pii/ S1360859214001946

7. Kluitenberg B, Middelkoop M Van, Diercks R, Worp H Van Der. What are the Differences in Injury Proportions Between Different Populations of Runners?? A Systematic Review and Meta-Analysis. Sport Med [Internet]. 2015;45:1143-61. Available from: http://dx.doi.org/ 10.1007/s40279-015-0331-x

8. Krabak BJ, Waite B, Lipman G. Evaluation and Treatment of Injury and Illness in the Ultramarathon Athlete. Phys Med Rehabil Clin N Am. 2014;25(4):845-63.

9. Fallon KE. Musculoskeletal injuries in the ultramarathon?: the 1990 Westfield Sydney to Melbourne run. Br J Sport Med. 1996;30:319-23.

10. Hoffman MD, Stuempfle KJ. Muscle Cramping During a 161-km Ultramarathon: Comparison of Characteristics of Those With and Without Cramping. Sport Med - Open [Internet]. 2015;1(1):24. Available from: http://www.sportsmedicine-open.com/content/1/1/24

11. Hutson M. Medical implications of ultra marathon running: observations on a six day track race. Brit J Sport Med. 1984;18(1):44-5.
12. White GE, Wells GD. Cold-water immersion and other forms of cryotherapy: physiological changes potentially affecting recovery from high-intensity exercise. Extrem Physiol Med [Internet]. 2013;2(1):26. Available from: http://www.extremephysiolmed.com/content/2/1/26

13. Nelson N. Delayed onset muscle soreness: Is massage effective? J Bodyw Mov Ther [Internet]. 2013;17(4):47582. Available from: http://dx.doi.org/10.1016/j. jbmt.2013.03.002

14. Roberts LA, Nosaka K, Coombes JS, Peake JM. Cold water immersion enhances recovery of submaximal muscle function following resistance exercise. Am J Physiol Regul Integr Comp Physiol [Internet]. 2014;(22): ajpregu.00180.2014-. Available from: http://ajpregu.physiology.org/content/early/2014/08/08/ajpregu.00180.2014

15. Pritchard KA, Saliba SA. Should Athletes Return to Activity After Cryotherapy? J Athl Train. 2014;49(1):95-6.

16. Meeusen R, Lievens P. The Use of Cryotherapy in Sports Injuries. Sport Med. 1986;414:398-414.

17. Halson SL, Quod MJ, Martin DT, Gardner AS, Ebert TR, Laursen PB. Physiological Responses to Cold Water Immersion Following Cycling in the Heat. Int J Sports Physiol Perform. 2008;3:331-46.

18. Hofstede H, Franke TPC, Eijk RPA Van, Backx FJG, Kemler E, Huisstede BMA. Physical Therapy in Sport In training for a marathon?: Runners and running-related injury prevention. Phys Ther Sport [Internet]. 2020;41:80-6. Available from: https://doi.org/10.1016/j.ptsp.2019.11.006

19. Baxter C, Naughton LRM, Sparks A, Norton L, Baxter C, Naughton LRM, et al. Impact of stretching on the performance and injury risk of long-distance runners. Res Sport Med [Internet]. 2016;00(00):1-13. Available from: http://dx. doi.org/10.1080/15438627.2016.1258640

20. Khodaee M, Ansari M. Common Ultramarathon Injuries and Illnesses?: Race Day Management. Curr Sports Med Rep. 2012;11(6):290-7.

21. Siqueira HP. Análise das alterações fisiológicas provenientes da massagem clássica em função do tempo de aplicação. Rev PIBIC. 2006;3(2):59-72.

22. Julie M, Douglas J, Chad J, Joseph M. Ice-Water Immersion and Cold-Water Immersion Provide Similar Cooling Rates in Runners With Exercise-Induced Hyperthermia. J Athl Train. 2002;37(2):146-50.

23. White GE, Rhind SG, Wells GD. The effect of various cold water immersion protocols on exercise - induced inflammatory response and functional recovery from high - intensity sprint exercise. Eur J Appl Physiol. 2014;114(11):2353-67.

24. Woods K, Bishop P, Jones E. Warm-Up and Stretching in the Prevention of Muscular Injury. Sport Med. 2007;37 (12):1089-99.

25. Weijer V, Gorniak GC, Shamus E. The Effect of Static Stretch and Warm-up Exercise on Hamstring Length Over the Course of 24 Hours. J Orthop Sport Phys Ther. 2003;33:727-33.

26. Ogura Y, Miyahara Y, Naito H, Katamoto S, Aoki J. Duration of static stretcjing influences muscle force production in hamstring muscles. J Strength Cond. 2007;21(3):788-92.

27. Bezerra E. Avaliando o Poder do Teste Estatístico e Calculando o Tamanho do Efeito (f de Cohen) [Internet]. 2018 
[cited 2019 Oct 18]. p. 3-7. Available from: http://www. gpces.com.br

28. Dupuy O, Douzi W, Theurot D, Bosquet L, Dugué B. An Evidence-Based Approach for Choosing Post-exercise Recovery Techniques to Reduce Markers of Muscle Damage, Soreness, Fatigue , and Inflammation: A Systematic Review With Meta-Analysis. Front Physiol. 2018;9 (April):1-15.

29. Winters M, Eskes M, Weir A, Bakker EWP. Treatment of Medial Tibial Stress Syndrome: A Systematic Review. Sport Med. 2013;43(12):1315-33.

30. Craig DI. Medial Tibial Stress Syndrome?: Evidence-Based Prevention. J Athl Train. 2008;43(3):316-8.

31. Andersen L, Jay K, Andersen C, Jakobsen M, Sundstrup E, Topp R, et al. Acute effects of massage or active exercise in relieving muscle soreness: randomized controlled trial. J Strength Cond. 2013;27(12):3352-9.

32. Wang H, Keck JF. Foot and Hand Massage as an Intervention for Postoperative Pain. Pain Manag Nurs. 2004;5 (2):59-65.

33. Nelson N. Delayed onset muscle soreness?: Is massage effective?? J Bodyw Mov Ther [Internet]. 2013;17(4):47582. Available from: http://dx.doi.org/10.1016/j. jbmt.2013.03.002

34. Bleakley C, Mcdonough S, Gardner E, Gd B, Jt H, Gw D. Cold-water immersion (cryotherapy) for preventing and treating muscle soreness after exercise (Review). Cochrane Database Syst Rev. 2012;(2):1-132.
35. Wilson LJ, Cockburn E, Paice K, Sinclair S, Faki T, Hills FA, et al. Recovery following a marathon?: a comparison of cold water immersion, whole body cryotherapy and a placebo control. Eur J Appl Physiol [Internet]. 2017;0(0):0. Available from: http://dx.doi.org/10.1007/s00421-0173757-z

36. Herbert R, de Noronha M. Stretching to prevent or reduce muscle soreness a er exercise (Review). Cochrane Database Syst Rev. 2007;(4):1-28.

37. "American College of Sports Medicine." Distúrbios causados pelo frio e pelo calor durante corridas de longa distância. Rev Bras Med do Esporte. 1999;5(3):108-19.

\section{Corresponding author}

Priscila dos Santos Bunn: Avenida Brasil, 10.590, Penha, CEP 21.012-350, Rio de Janeiro, RJ, Brazil.

E-mail: priscilabunn@yahoo.com.br.

Manuscript received on August 14, 2019

Manuscript accepted on March 9, 2020

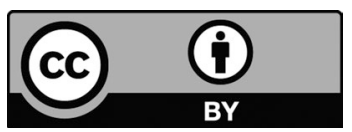

Motriz. The Journal of Physical Education. UNESP. Rio Claro, SP, Brazil - eISSN: 1980-6574 - under a license Creative Commons - Version 4.0 